\title{
Proximal Femoral Nail: A Boon for Pertrochanteric and Subtrochanteric Fractures
}

\author{
Harindra Himanshu ${ }^{1}$, Mani Bhushan Prasad ${ }^{2}$, Ajay Kumar Verma ${ }^{3}$. \\ ${ }^{1}$ Senior Resident, ${ }^{2}$ Assistant Proessor, ${ }^{3}$ Assistant Professor \\ Department of Orthopaedics, RIMS, Ranchi -834009, Jharkhand, India.
}

\begin{abstract}
Pertrochanteric fractures are of intense interest globally. Incidence has increased significantly during recent decades and this tendency will probably continue to rise in near future due to increased span of life. Before the introduction of suitable fixation devices, the treatment was predominantly conservative. This conservative approach has now fallen into disrepute because of the high complication rate, making operative management preferred treatment. The present study is undertaken to study the role of surgical management and assess its functional outcome in Pertrochanteric and subtrochanteric fracture. The study was carried out in patients treated for closed displaced pertrochanteric and subtrochanteric fracture, from August 2013 to Jan 2016. A total of 74 patients with closed pertrochanteric and subtrochanteric fracture were included in the study. Patients were between the age group of 20 to 90 years with 44 males and 30 females. Fractures were classified according to Boyd and Griffin and Seinsheimer's for intertrochanteric and subtrochanteric fractures respectively. Functional Outcome was evaluated according to HARRIS HIP SCORE, with mean score of 77.6. Excellent score was noted in 21.6\%, Good in 35\%, Fair in 31.6\%, Poor in $6.6 \%$ and failed in 5\%. PFN is a good implant for intertrochanteric and subtrochanteric fracture of the femur. Minimal exposure, lesser blood loss, closed technique, shorter operative time, less morbidity, with mechanical advantages of rotational stability , possibility of dynamic or static distal locking and early return to preoperative status enhance the efficacy of treatment.
\end{abstract}

Keywords: pertrochanteric fractures, intertrochanteric fractures, subtrochanteric fractures, internal fixation, Boyd and Griffin

\section{Introduction}

Pertrochanteric fractures are most frequently operated fracture and are of intense interest globally. Its serious health resource issue because of the high cost of care required after injury. The reason for the high cost of care is primarily related to the poor recovery of functional independence after conventional fracture care in many patients ${ }^{1}$. Pertrochanteric fractures are those occurring in the region extending from the extra capsular basilar neck region to the region along the lesser trochanter before the development of the medullary canal. Intertrochanteric and peritrochanteric are generic terms for pertrochanteric fractures ${ }^{1}$. Subtrochanteric fractures typically occur in the proximal femur between the inferior aspect of the lesser trochanter and a distance of about $5 \mathrm{~cm}$ distally ${ }^{2}$. In 1997 Gullberg et al. estimated that the future incidence of hip fracture worldwide would double to 2.6 million by 2025 , and 4.5 million by $2050^{3}$. The percentage increase will be greater in men (310\%) than women $(240 \%)$. In $199026 \%$ of all hip fractures occurred in Asia, whereas this figure could rise to $37 \%$ in 2025 and $45 \%$ in $2050{ }^{4}$. Hagino et al. Reported a lifetime risk of hip fracture for individuals at 50 years of age of $5.6 \%$ for men and $20 \%$ for women ${ }^{5}$. Before the introduction of suitable fixation devices, the treatment was predominantly conservative but this approach has now fallen into disrepute because of the high complication rate $^{6,7}$. The common problems of prolonged immobilization, i.e : decubitus ulcers, U.T.I., joint contractures, pneumonia and thromboembolism contribute to the high mortality rate ${ }^{7}$. The increased incidence of varus deformity and shortening results in poor function, making operative management preferred treatment. Operative treatment for hip fractures was introduced in 1950s with expectation of improved functional outcome and reduced complications ${ }^{8,9}$. Since then, a variety of treatment options have evolved like Extramedullary, Intramedullary implants, External fixator and Arthroplasty. Internal treatment of these fracture has gained wide spread acceptance but the problems i.e. Malunion, nonunion, implant failure, refracture and infection encountered after surgical correction, have prompted continued development of new devices and treatment programmes. The advantages of an intramedullary nail include improved biomechanics ( shortned lever arm ), smaller incisions with minimal soft tissue damage, decreased blood loss, decreased femoral neck shortening ${ }^{10}$. In 1996 A0/ASIF developed the PFN, intramedullary device for treatment of pertrochanteric, and subtrochanteric fractures. PFN is made up of ultra strength stainless steel alloy (316L) which has sufficient strength to allow early weight bearing even in unstable proximal femoral fractures ${ }^{11,12}$. The Indian versions are available and have been used in our study. PFN is $240 \mathrm{~mm}$ long with proximal $8 \mathrm{~cm}$ has constant diameter of 14 $\mathrm{mm}$ in all sizes of nail, irrespective of distal diameter . Distal diameters of nail are available in range of 9,10 , 
$11,12 \mathrm{~mm}$ with $6^{\circ}$ angles between proximal and distal parts and is situated at $11 \mathrm{~cm}$ from the tip of nail. PFN uses 2 -screw configuration ${ }^{13}$. i.e lag screw \& antirotational screw ${ }^{14}$. Nails of $130^{0} \& 135^{0}$ are available but $135^{\circ}$ is preferred. Lag screw or cervical screw is canulated with $7.9 \mathrm{~mm}$ dimension, and is inserted through distal slot on proximal aspect of nail. Antirotational screw or hip pin is canulated with $6.4 \mathrm{~mm}$ dimension and is inserted through proximal slot of nail. Distal end of nail allows Static and dynamic locking.

\section{Aims And Objectives.}

This study is intended to evaluate the outcome of fixation of pertrochanteric and subtrochanteric fracture using Proximal femoral nail at our institute with respect to -

1. Stability at fracture site .

2. Union at fracture site.

3. Early mobilization.

4. Functional restoration .

5. Complication.

\section{Materials And Method.}

The study was carried out in patients treated for closed displaced pertrochanteric and subtrochanteric fracture, from August 2013 to Jan 2016. A total of 74 patients with closed pertrochanteric and subtrochanteric fracture were included in the study.

\section{Inclusion Criteria}

1. Close displaced pertrochanteric and subtrochanteric femur fractures.

2. Skeletally mature patients.

3. No medical contraindication for anesthesia.

4. Patients willing to give written and informed consent for participation in the study .

\section{Exclusion Criteria}

1. Pertrochanteric and subtrochanteric femur fractures in polytrauma patients .

2. Open fractures of proximal femur .

3. Pathological fractures.

4. Active skin lesion $\&$ infection at operative site .

5. Skeletally immature patients .

6. Patients neurologically unstable (Glasgow Coma Scale < 12)

7. Medical contraindication to surgery or anaesthesia.

8. Injuries around the knee, ankle \& foot in the ipsilateral side

9. Ipsilateral fracture shaft femur and tibial.

After taking detailed history, local and general examination was done. Distal neurovascular survey was done and recorded. During the evaluation period, below knee skin traction was applied and limb was elevated on the Bohler Braun splint .After taking appropriate $\mathrm{x}$ ray, the fractures were classified according to Boyd and Griffin and Seinsheimer's for intertrochanteric and subtrochanteric fractures respectively. Tentative diameter of nail was determined by measuring the inner diameter between two cortices at the level of isthmus of femur. After pre operative medications and spinal anaesthesia, all patients were positioned supine on fracture table. Closed reduction of fracture was performed under image intensifier, if closed reduction fails , open reduction was performed and $\mathrm{k}$ - wire was passed to hold the reduction making sure it dose not interfere with the guide wire. After proper incision, entry point was made at the tip of the greater trochanter, halfway between its anterior and posterior extent and guide wire was introduced .Reaming was done with flexible reamer and nail of appropriate dia. was introduced over the guide wire. Two proximal screws of 8 and $6 \mathrm{~mm}$ was introduced in femoral neck. $8 \mathrm{~mm}$ lag screw and $6 \mathrm{~mm}$ antirotational hip screw was placed in lower half and upper half of the neck on the antero-posterior view and centrally on the lateral view respectively . Length difference of $10 \mathrm{~mm}$ between the screws is maintained. Distal lock is done in static and dynamic mode. Wounds were closed in layers over negative suction drain, and removal after $48 \mathrm{hrs}$. During post operative, limb was elevated on bohler frame to reduce swelling. The wounds were inspected on the $3^{\text {rd }} \& 7^{\text {th }}$ post operative day. Stitches were removed on the 13th day. Wounds showing any suspicious signs of infection were treated with higher antibiotics \& subsequently by debridement. Blood transfusion was given if required.

\section{Postoperative Mobilization \& Rehabilitation}

- Day 1: Static quadriceps exercises .

- Day 2: Knee flexion with the patient sitting by the edge of the bed . 
- Day 3: Patient was put on CPM machine for passive range of motion 0 to 30 degrees and was gradually increased depending on pain tolerance and continued till 90 degrees of flexion was achieved.

- Day 4-5: Walking with the aid of a walker without weight bearing .

- Day 13: The patients were discharged and instructed to walk ( non weigtht bearing) with a walker, sit on chair or high stool .

\section{Follow Up Protocol}

All patients were followed for at least six months . The follow up visits were done at: 1,3,6,12,18,24 months . On every visit clinical evaluation was done by Harris Hip score and radiological by X-ray . Radiologically the presence of callus, and complications were seen.

\section{Observation And Results}

The Study involved 74 patients of pertrochanteric and subtrochanteric fractures, which were operated in Orthopeadic department in our hospital. The age distribution of patients ranges from 20 to 90 years. The average age was 64.04 yrs. Youngest was 21 while oldest was 81 years $.64 \%$ of patients belong to 60 to 80 years group. Mode of injury in 69 (93.24\% ) was fall (fall at home, work place etc.) and 05 patients $(6.7 \%)$ road traffic accident. Left Side was involve in $35(47.2 \%)$ and right in $39(52.7 \%)$. The Study involved 44 $(40.5 \%)$ males and $30(59.4 \%)$ female. Out of the 74 patients ,62 $(81.08 \%)$ were Intertrochanteric and rest 12 (18.9\%) was Subtrochanteric . According to Boyd and Grrifin classification we have 30 (48.3\%) Type 1,18 (29\% ) Type 2, $02(3.22 \%)$ Type 3 and , $12(19.35 \%)$ Type 4 Intertrochanteric fractures but in Seinsheimer classification we have none in Type 1, $10(83.3 \%)$ in Type 2, 01 (8.3\% ) in Type $3,01(8.3 \%)$ in Type 4, none in Type 5. $55(74.3 \%)$, out of 74, $55(74.3 \%)$ were operated within 5 days and rest $19(25.6 \%)$ in next 6-10 days. Operating time for $42(56 \%$ ) cases was between 1 to 2 hours. Operating time decreased with increasing number of cases and familiarity with the implant system. Close reduction was tried in all the patients but successfuliy achieved in $64(86.4 \%)$, and in rest $10(13.5 \%)$ open reduction was done. Nails are available of different sizes ranging from 9 to $12 \mathrm{~mm}$. In Indian population average diameter of medullary canal is found to between $9-10 \mathrm{~mm}^{15} .9 \mathrm{~mm}$ nails were used in $19,10 \mathrm{~mm}$ in $38,11 \mathrm{~mm}$ in 16 cases,and $12 \mathrm{~mm}$ in 1 case. In our study average diameter of nail used was $9.4 \mathrm{~mm}$. Two types of screw were used in pfn, lag screw of $8 \mathrm{~mm}$ and derotation screw of $6 \mathrm{~mm}$ size but length varies. Lag screw used were in range of $75 \mathrm{~mm}$ to $105 \mathrm{~mm}$. we have used $75 \mathrm{~mm}$ screw in $4(5.4 \%), 80 \mathrm{~mm}$ in $2(2.7 \%), 85 \mathrm{~mm}$ in $14(18.9 \%), 90 \mathrm{~mm}$ in $27(36.4 \%), 95 \mathrm{~mm}$ in $16(21.6 \%), 100 \mathrm{~mm}$ in $7(9.4 \%)$ and $105 \mathrm{~mm}$ in 4 cases(5.4\%). Anti rotation screw used were in range of 65 to $95 \mathrm{~mm}$. $65 \mathrm{~mm}$ screw in 3 cases $(4.05 \%), 70 \mathrm{~mm}$ in $5(6.75 \%), 75 \mathrm{~mm}$ in $7(9.45 \%), 80 \mathrm{~mm}$ in $24(32.4 \%)$, $85 \mathrm{~mm}$ in 17 cases (22.9\%), $90 \mathrm{~mm}$ in $14(18.9 \%)$ and $95 \mathrm{~mm}$ in 3 cases (4.05\%). Associated injuries are seen in 5 cases, lower end radius fracture in $04(5.4 \%)$, while both bone forearm fracture $01(1.3 \%)$.. Various complications are seen during intra operative and post operative follow up time. Difficulty in distal locking in $01(1.3 \%)$ patient intraop and rest in post op follow up i.e: Cut out of neck screw in $03(4.05 \%), \mathrm{Z}$ effect in 05 $(6.7 \%)$, Reverse $\mathrm{Z}$ effect in $02(2.7 \%)$, Bolt breakage in $01(1.3 \%)$, Fracture greater trochanter in $01(1.6 \%)$ . Revision surgery required in $03(4.05 \%)$. Since $64 \%$ of patients were $>60$ years, various Systemic complications i.e: chest infection, respiratory distress, urinary tract infection seen in 1 ( $1.3 \%$ ) each and Local complications i.e: superficial wound infection occurs in $1(1.3 \%)$. In 54 ( $90 \%)$ patients union occurs between $16-20$ weeks time frame. Average time for union was 17.6 weeks (4.42 month). Death occurs in 05 $(6.7 \%)$ patients , not related to surgery but mostly due to medical co-morbidities . Patients were evaluated according to Harris Hip Score, with mean score of 77.6. Excellent score was noted in 21.6\%, Good in 35\%, Fair in $31.6 \%$, Poor in $6.6 \%$ and Failed in $5 \%$.

\section{Discussion.}

Search for ideal implant for treatment of fractures around trochater continues. Internal fixation of such fractures permits early rehabilitation with good functional recovery, and hence has become the treatment of choice for virtually all trochanteric fractures. In this study an attempt was made to evaluate the management of pertrochanteric and subtrochanteric fractures using proximal femoral nail (PFN).The study group included 44 males \& 30 females with male: female ratio of 1.3:1. The average age of patients was 64.04 years . The most common age group being 60-80 years. Fractures were classified as per the Boyd and Griffin and Seinsheimer classification for Intertrochanteric and Subtrochanteric fractures respectively.Stable fracture pattern was seen in $29(48.3 \%)$, while unstable pattern in $31(51.8 \%)$ intertrochanteric fractures .Unstable fractures were seen more frequently in females than males. In other studies done by Tyllianakis,Panagopoulos ${ }^{16}$, Christian Boldin; Franz J. Seibert ${ }^{12}$, Pavelka T, Kortus J ${ }^{17}$, J. Pajarinen,J. Lindahl ${ }^{18}$, W. M. Gadegone \& Y. S. Salphale ${ }^{11}$ avg. age incidence was $73,69,80,69$ respectively, while average incidence in our study being 64.04 years indicated younger Indian-population is at risk of fracture. In other series of Tyllianakis, Panagopoulos ${ }^{16}$, Pavelka T, Kortus $\mathrm{J}^{17}$, J. Pajarinen,J. Lindahl ${ }^{18}$ the $\mathrm{m} / \mathrm{f}$ ratio was $0.607,0.6,0.33$ respectively, while $\mathrm{m} / \mathrm{f}$ ratio in our 
study was 1.3:1. Indicated males are more involved than female because males are more active, outgoing and engaged in more out door activities like agriculture, driving of motor vehicles and thus more prone to accidents I fall and females are engaged more in household activities. When stability and unstability of intertrochanteric fractures are concern, similar results are seen in Pavelka T, Kortus J ${ }^{17}$ and W. M. Gadegone.Y.Salphale ${ }^{11}$ studies. Superficial would infection at the entry site and proximal lock site was seen in early post operative period within 14 to 21 days but no case of deep infections is seen. An early debridement with higher antibiotics based on culture and sensitivity. Union occurred \& none required implant removal . This may be attributed to low immunity status because of leprosy, diabetes mellitus and low socioeconomic status. During follow up systemic complicatios i.e chest infection, respiratory distress and urinary tract infection (UTI) occurred. Chest infection and respiratory distress occurred because of COPD, as they were chronic bidi smoker. Urinary tract infection were due to prostatic disease, prolonged catheterization etc.. Appropriate treatment were given, after consulting physician. $5(6.7 \%)$ deaths occurred after three months of surgery not related to operative interference.

Reported mortality rates for the first postoperative year is around $20-25 \%{ }^{15}$. Time of union ranges from 12 to 20 weeks, with average time of union was 17.6 weeks. Clinically, absence of pain at fracture site and radiologically the presence of bridging callus at fracture site are the signs of fracture healing. Similar results were seen in other studies by F.G.M. Khallaf A. Al-Rowaih. ${ }^{19}$, Christian Boldin; Franz J. Seibert ${ }^{12}$, Banan H, Al-Sabti A, Jimulia T ${ }^{20}$, W. M. Gadegone \& Y. S. Salphale ${ }^{11}$, Harish kumar jain ${ }^{21}$ with average time of union was 4 month, 5 month, 4 month, 4.5 month and ,10 to 18 week respectively. Like every other procedure, we faced different implant related complications. we have encountered ' $Z$ ' effect in $5(6.7 \%)$, reverse ' $Z$ ' effect in $2(2.7 \%)$, Cut out of the antirotational screw in $3(4.05 \%)$, Antirotational screw breakage in $1(1.6 \%)$, Non union in $1(1.6 \%)$ and, Failure to put distal screw in $1(1.6 \%)$. The cause of $\mathrm{Z}$ effect and reverse $\mathrm{Z}$-effects is not properly understood but the probable cause is due to fracture fixed in varus position, severe medial comminution, inappropriate entry point of the nail, poor bone quality ${ }^{22}$ leading to differential compression \& tensioning of two screws . Migration of the screws due to severe osteoporosis was detected during the follow up in 7 patients . ' $Z$ effect' may be seen because of migration of hip pins into the joint ${ }^{11}$ as seen in 3 of our cases. In our series the reason for $\mathrm{Z}$ effect and reverse $\mathrm{Z}$-effect may be due to osteoporosis, unstable fractures with severe medial communition, and early weight bearing . Antirotational screw was broken in 1 case on $3^{\text {rd }}$ follow up. Although patient was obese, and had type 4 intertrochanteric fracture with extension into subtrochanteric region but on taking detailed history it was found that patient started unpermitted early full weight bearing i.e. immediately after discharge from hospital. The fact was kept hidden by him on $1^{\text {st }}$ and $2^{\text {nd }}$ follow up. This complication was seen on $3{ }^{\text {rd }}$ follow up on $\mathrm{x}$ ray. Subsequently patient had developed non union .But despite of broken implant patient was walking with support. Unstable Intertrochanteric fracture especially badly communited are common situation where fracture goes into non union along with lot of morbidity at times mortality ${ }^{15}$. Failure to put distal screw was due to zig and nail hole mismatch. This mismatch was attributed to the old zig which was roughly handled by many surgeons. Patients were evaluated according to Harris Hip Score, with mean score of 77.6. Excellent to good results were seen in $56 \%$, good to fair in $66 \%$, poor results in $6.6 \%$.In other studies of W. M. Gadegone \& Y. S. Salphale ${ }^{11}$, Excellent to good results were seen in $82 \%$, in Harish kumar jain ${ }^{21}$, Excellent to good results in $83 \%$, and in Ranjeetesh Kumar \& R.N. Singh, shows Mean Harris hip score of 93. Our finding differ from other studies because of variation in local epidemiological factors i.e . low literacy rate, low socio economic factors etc.

\section{Conclusion}

In conclusion PFN is a good implant for intertrochanteric and subtrochanteric fractures with advantages of smaller exposure, lesser blood loss, closed technique, shorter operative time, less morbidity, with mechanical advantages of rotational stability and possibility of dynamic or static distal locking. Fracture united in almost all the cases and postoperative functional outcome was good. The number of complications was acceptable and comparable with other fracture fixation system. Procedure is technically demanding with difficulty in early cases but gradually with learning and improvement in technique, complications can be avoided. Operative management which allows early rehabilitation and offers to the patient the best chances for functional recovery is the treatment of choice for virtually all peri-trochanteric fractures.

\section{Bibilography}

[1]. Thomas A. Russell . Inter Trochanteric Fractures. In: Bucholz, Robert W. ; Heckman, James D. ; Court-Brown, Charles M. ; Tornetta, Paul eds. Rockwood And Green's Fractures In Adults, 7th Edition. Philadelphia ; poi,lkim1`Lippincott Williams \& Wilkins. 2010. pg 1597.

[2]. George J. Haidukewych, Joshua Langford . SubTrochanteric Fractures. In: Bucholz, Robert W. ; Heckman, James D. ; CourtBrown, Charles M. ; Tornetta, Paul eds . Rockwood And Green's Fractures In Adults, 7th Edition. Philadelphia ; Lippincott Williams \& Wilkins. 2010. pg 1641

[3]. Gullberg B, Johnell O, Kanis JA. World-wide projections for hip fracture. Osteoporos Int 1997;7(5):407-413. 
[4]. Melton LJ 3rd, Kearns AE, Atkinson EJ, et al. Secular trends in hip fracture incidence and recurrence. Osteoporos Int 2009;20(5):687-694.

[5]. Hagino H, Furukawa K, Fujiwara S, et al. Recent trends in the incidence and lifetime risk of hip fracture in Tottori, Japan. Osteoporos Int 2009;20(4):543-548.

[6]. Kyle RF, CabanelaME,RusellTA, et al. Fractures of the proximal part of the femur. Instr Course Lect 1995; 44:227-253.

[7]. Zuckerman JD, Comprehensive care of orthopaedic injuries in the elderly, Baltimore : Urban and Schwarzenberg, 1990 .

[8]. Schumpelick W, Jantzen PM: A new principle in the operative treatment of trochanteric fracture of the hip, J.Bone Joint Surg 1988, 70-A:1297-303.

[9]. Massie WK: Fracture of the Hip, J.Bone Joint Surg 1964, 46-A: 658-90

[10]. John C. Weinlein . Fractures And Dislocations Of Hip; Intertrochanteric Femoral Fractures. In : Canale, S. Terry. ; Beaty, James H. Campbell's Operative Orthopaedics, 12 th edition. Philadelphia ; Elsevier Mosby . 2013 . pg 2742.

[11]. W. M.Gadegone \& Y.S.Salphale.Proximal femoral nail - an analysis of 100 cases of proximal femoral fractures with an average follow up of 1 year. International Orthopaedics (SICOT) (2007) 31:403-408.

[12]. Christian Boldin, Franz J Seibert, Florian Fankhauser, Gerolf Peicha,Wolfgang and Rudolf Szyszkowitz .The proximal femoral nail (PFN) - a minimal invasive treatment of unstable proximal femoral fractures.Acta Orthop Scand 2003; 74 (1): $53-58$ 53.

[13]. T Morihara, Y Arai, S Tokugawa.Proximal femoral nail for treatment of trochanteric femoral fractures. Journal of Orthopaedic Surgery 2007;15(3):273-7.

[14]. Wasudeo M Gadegone, Yogesh S Salphale. Short proximal femoral nail fixation for trochanteric fractures. Journal of Orthopaedic Surgery 2010;18(1):39-44

[15]. Babhulkar Sudhir S. Management of trochanteric Fractures Department of -Orthopaedics, Indira Gandhi Medical College, Nagpur, INDIAN JOURNAL OF ORTHOPAEDICS October 2006 volume 40: Number 4: P. 210-218.

[16]. Minos TYLLIANAKIS, Andreas PANAGOPOULOS, Andreas PAPADOPOULOS, Socratis PAPASIMOS, Konstantinos MOUSAFIRIS.Treatment of extracapsular hip fractures with the proximal femoral nail(PFN) : Long term results in 45 patients. Acta Orthopædica Belgica, Vol. 70 - 5 - 2004.

[17]. Pavelka T, Kortus J, Linhart M. Osteosynthesis of proximal femoral fractures using short proximal femoral nails. Acta Chir Orthop Traumatol Cech. 2003;70(1):31-8.

[18]. J. Pajarinen,J. Lindahl,O. Michelsson,V. Savolainen, E. Hirvensalo. Pertrochanteric femoral fractures treated with a dynamic hip screw or a proximal femoral nail. J Bone Joint Surg [Br] 2005;87-B:76-81

[19]. F.G.M. Khallaf A. Al-Rowaih H.F. Abdul-Hamid. Results of Subtrochanteric Fractures Treated with Dynamic Hip Screw and Dynamic Condylar Screw. Med Principles Pract 1998;7:283-291.

[20]. Banan H, Al-Sabti A, Jimulia T, Hart AJ The treatment of unstable, extracapsular hip fractures with the AO/ASIF proximal femoral nail (PFN)--our first 60 cases.Injury. 2002 Jun;33(5):401-5.

[21]. Harish Kumar Jain , Suresh Dhakar, Manoj Sharma , Mukul Jain , Hemlata Sharma.Efficacy of proximal femoral nail in peritrochanteric femoral fractures of elderly patients. Int J Biol Med Res. 2012; 3(3): 1910-1913.

[22]. Pires RE, Santana EO Jr, Santos LE, Giordano V, Balbachevsky D, Dos Reis FB.Failure of fixation of trochanteric femur fractures: Clinical recommendations for avoiding Z-effect and reverse Z-effect type complications. .Patient Saf Surg. 2011 Jun 22; 5:17.

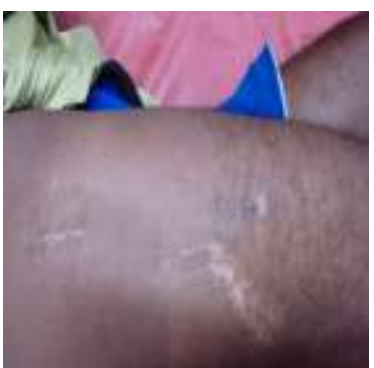

Skin Incision

\section{Case Clinical Photograph}

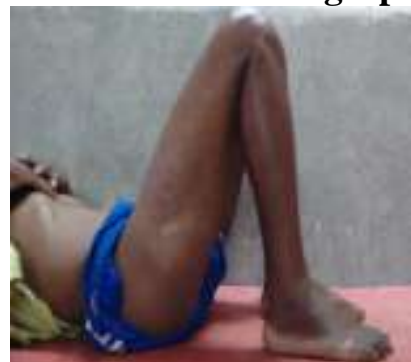

Flexion At Hip Jt.

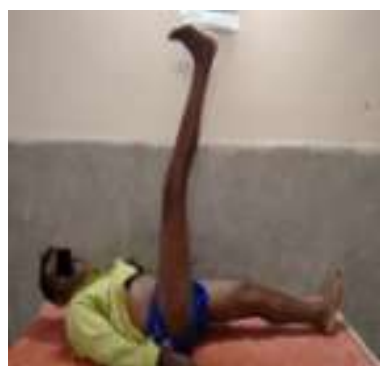

Straight Leg Raising

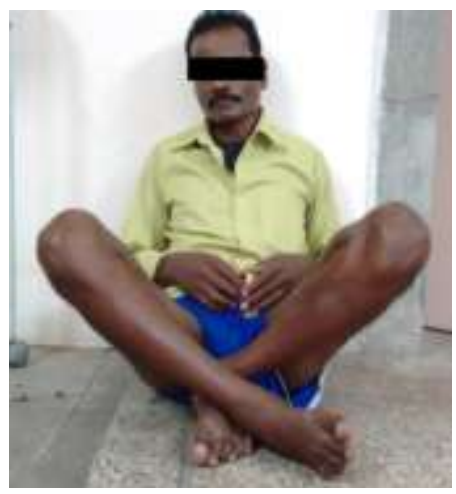

Cross Leg Sitting Operated Side

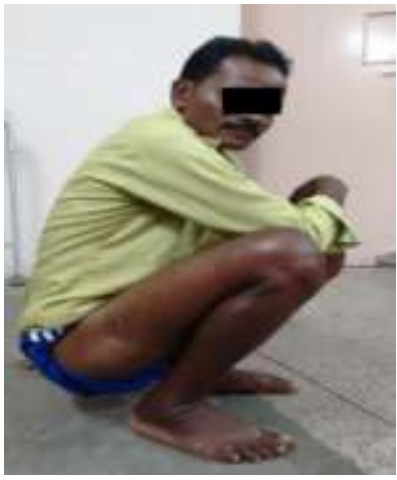

Squatting

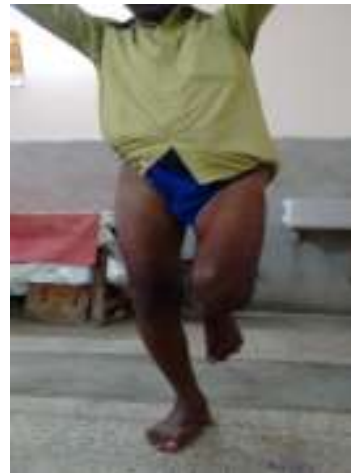

Weight Bearing On

\section{CASE X - RAY}




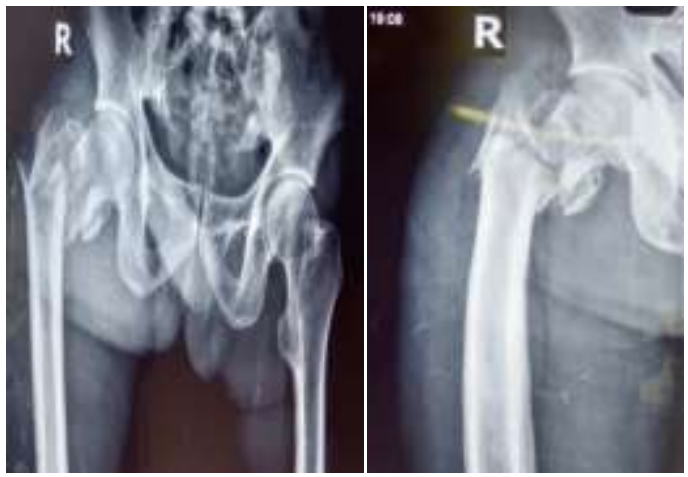

X Ray Pelvis Ap \& Lateral View

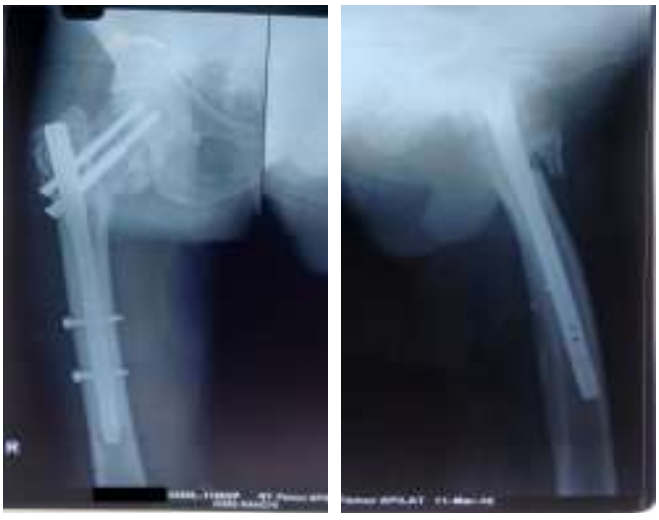

1 St Monthpost Op Ap \& Lateral

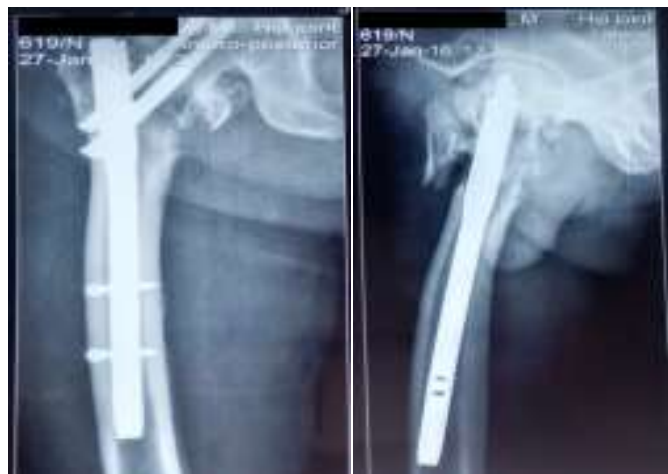

Immediate Post Op Ap \& Lateral

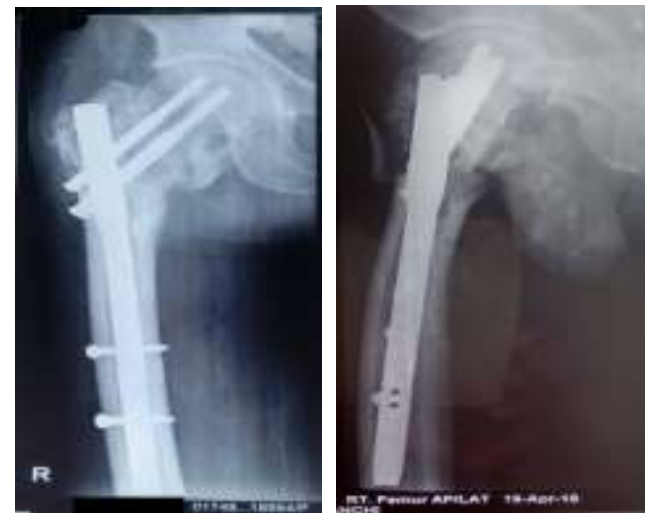

3 Rd Month Post Op Ap \& Lateral
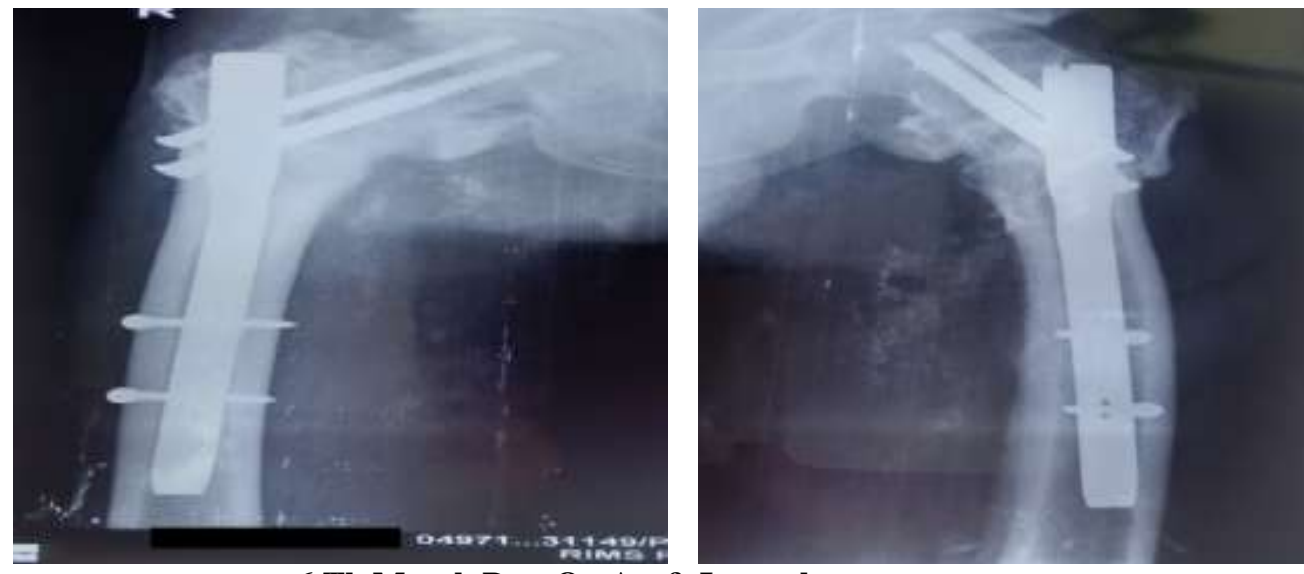

6 Th Month Post Op Ap \& Lateral

Complications Radiograph.

1. Z' Effect.

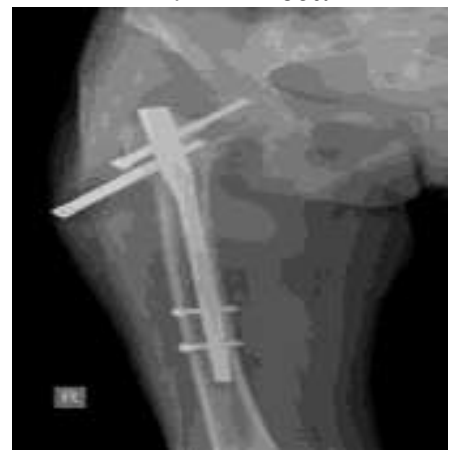

3.Cut out of antirotational pin.
2. Reverse Z' Effect.

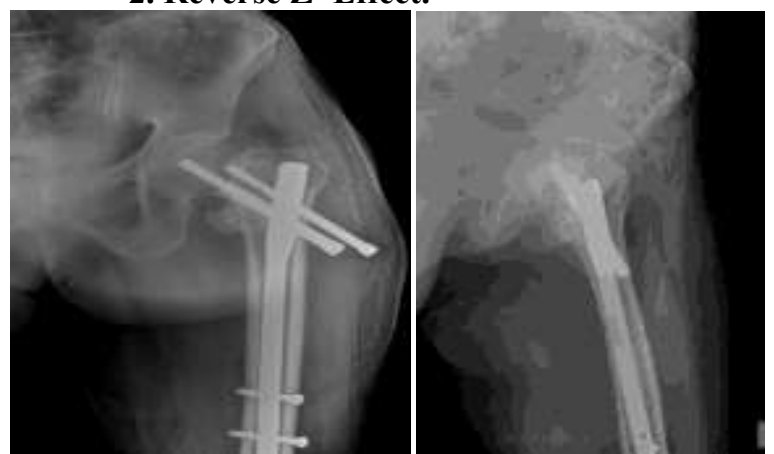

4.Screw broken with non union. 

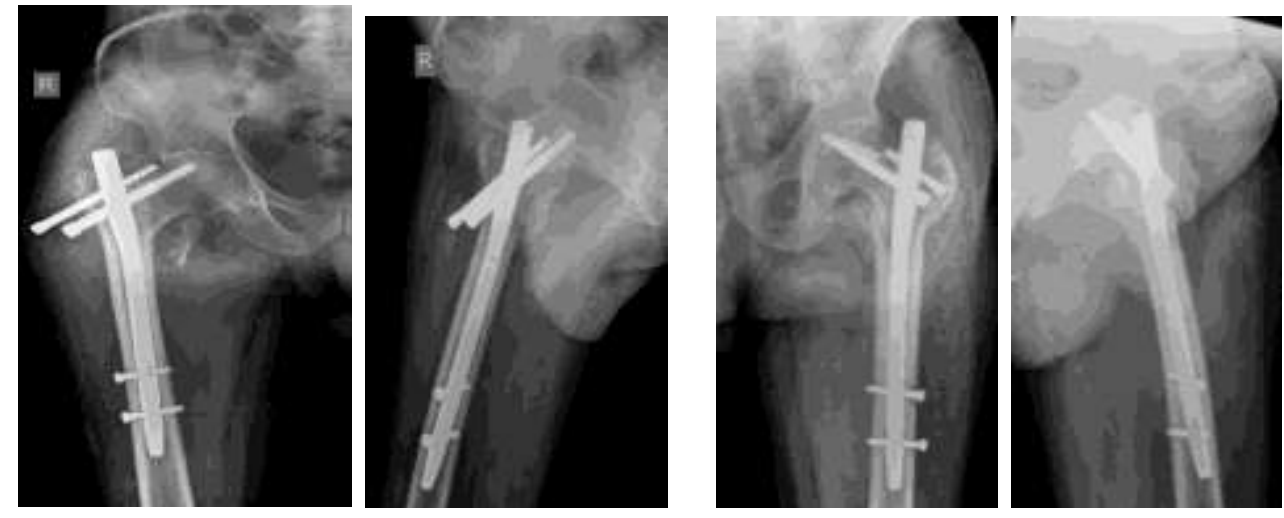

5.Lateral migration of both proximal screws.
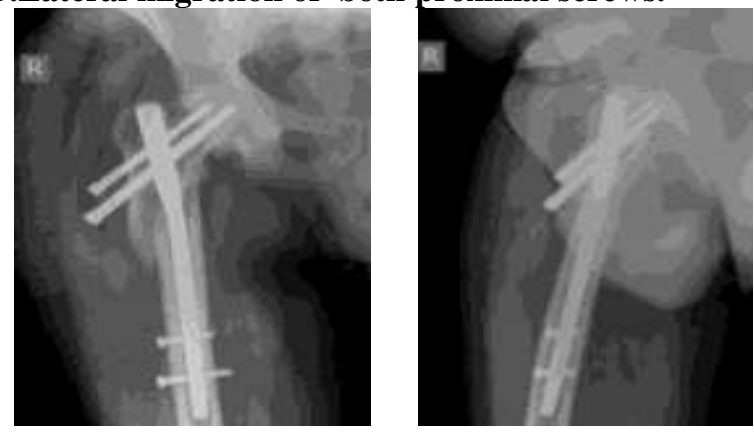

6.Failure to put distal screw

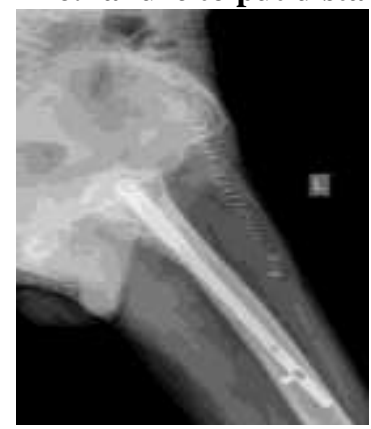

